\title{
Cell-secreted vesicles containing microRNAs as regulators of gamete maturation
}

\author{
Juliano C da Silveira', Ana Clara F C M de Ávila', Hannah L Garrett ${ }^{2}$, Jason E Bruemmer ${ }^{2}$, Quinton A Winger ${ }^{2}$ and \\ Gerrit J Bouma² \\ 1Department of Veterinary Medicine, Faculty of Animal Sciences and Food Engineering, University of Sao Paulo, Pirassununga, Sao Paulo, Brazil \\ 2Department of Biomedical Sciences, College of Veterinary and Biomedical Sciences, Animal Reproduction and Biotechnology Laboratory, Colorado State \\ University, Fort Collins, Colorado, USA \\ Correspondence should be addressed to G J Bouma: Gerrit.Bouma@colostate.edu
}

\section{Abstract}

Mammalian gamete maturation requires extensive signaling between germ cells and their surrounding somatic cells. In the ovary, theca cells, mural granulosa cells, cumulus cells and the oocyte all secrete factors throughout follicle growth and maturation that are critical for ovulation of a high-quality oocyte with the competence to develop into an embryo. Similarly, maturation of sperm occurs as it transits the epididymis during which epididymal epithelium and sperm exchange secretory factors that are required for sperm to gain motility and fertility. Recent studies in a variety of species have uncovered the presence of cell-secreted vesicles in follicular fluid (microvesicles and exosomes) and epididymal fluid (epididymosomes). Moreover, these cell-secreted vesicles contain small non-coding regulatory RNAs called microRNAs, which can be shuttled between maturing gametes and surrounding somatic cells. Although little is known about the exact mechanism of how microRNAs are loaded into these cell-secreted vesicles or are transferred and modulate gene expression and function in gametes, recent studies clearly suggest that cell-secreted vesicle microRNAs play a role in oocyte and sperm maturation. Moreover, a role for cell-secreted vesicular microRNAs in gamete maturation provides for novel opportunities to modulate and discover new diagnostic markers associated with male or female fertility. This manuscript provides an overview of cellsecreted vesicles in ovarian follicular fluid and epididymal fluid and microRNAs and discusses recent discoveries on the potential function of cell-secreted vesicles as carriers of microRNAs in oocyte and sperm maturation.

\author{
Key Words \\ - microRNAs \\ - extracellular vesicles \\ - sperm \\ oocyte
}

\section{Introduction}

Proper cell function requires the coordinated regulation of a myriad of genes and proteins necessary for maintenance of tissue homeostasis and organism fitness. MicroRNAs are small non-coding RNA molecules that regulate gene expression and function by binding complementary sequences in target transcripts and either promoting degradation or inhibiting translation. It has been estimated that microRNAs regulate $10-50 \%$ of genes in the human genome (Lu \& Clark 2012). Moreover, a single microRNA can regulate hundreds of transcripts, and at the same time, a single transcript can be regulated by many microRNAs (reviewed in Lu \& Clark 2012). MicroRNAs thus are responsible for regulating and fine-tuning many gene regulatory networks, with the overall result of controlling 
cell differentiation, proliferation, apoptosis, metabolism, responsiveness and secretion. It is not surprising that microRNAs also play important roles in regulation of gene function in various aspects of reproductive biology, including development and function of the reproductive tracts, germ cell development and maturation, fertilization and early embryo development (reviewed in Luense et al. 2011, Hilz et al. 2016). The recent findings that microRNAs also are present in blood and can be transferred from one cell to another (e.g., György et al. 2011), adds another layer of intricacy of microRNA function in reproductive physiology.

A new mechanism in context of cell communication is the release and uptake of extracellular vesicles. Cells secrete a wide variety of membranous vesicles, often characterized by size, shape or content. Their nomenclature still is obscure and cell-secreted vesicles have been referred to as microparticles, ectosomes, shedding vesicles, microvesicles or exosomes (Cocucci \& Meldolesi 2015). The notion that cells release membrane-enclosed vesicles and these vesicles are present in extracellular space has existed for several decades (Raposo et al. 1996). Initially considered 'cellular garbage bags' and/or the result of cellular degeneration, it is now clear that cells release vesicles into extracellular fluid both constitutively and following induction. Moreover, these extracellular vesicles contain a variety of bioactive molecules, including mRNAs and microRNAs that can be transferred from one cell to another.

The presence of microRNAs in these vesicles and their transfer and uptake by target cells suggests these vesicles can have pronounced effects on the regulation of genetic networks and ultimately cell phenotype and function (Fevrier et al. 2004, Mathivanan et al. 2010). This review will focus on recent discoveries on the presence and potential function of cell-secreted or extracellular vesicles as carriers of microRNAs in oocyte and sperm maturation.

\section{Small non-coding microRNAs: an overview}

MicroRNAs are small, $18-24$ nt long non-coding RNA molecules that regulate target mRNA expression and function through base-pairing between a $\sim 8 \mathrm{nt}$ seed sequence and the 3' untranslated region (UTR) (Bartel 2009, Lee et al. 2009, Lu \& Clark 2012). The first step in microRNA biosynthesis is transcription of a microRNA gene by RNA polymerase II generating a primary transcript (pri-microRNA). Next, cropping of pri-microRNA by the RNase III endonuclease Drosha yields a $\sim 70$ nucleotide long precursor microRNA (pre-microRNA). The premicroRNAs are imperfect hairpin structures that are exported from the nucleus into the cytoplasm. In the cytoplasm, pre-microRNAs are processed further by the RNase III endonuclease Dicer into imperfect doublestranded RNA (dsRNA) complexes. The dsRNA complexes are loaded into a ribonucleoprotein complex called RNAinduced silencing complex (RISC), which consists of Argonaute proteins, and only retains the mature microRNA strand. Although Dicer is a critical enzyme involved in mature microRNA synthesis, pre-microRNAs can also be directly loaded into the RISC complex and processed by Argonaute 2 (Cheloufi et al. 2010). RISC forms a complex with target RNA and causes gene (transcript) silencing. Downregulation of target gene expression occurs by basepairing interaction with a mRNA target via one of the two mechanisms; mRNA cleavage if there is high sequence complementarity with the microRNA or translational repression if there is less sequence complementarity with the microRNA. MicroRNA binding sites reside in the 3' UTR (untranslated region) of mRNA transcripts; however, binding to the coding region of a target transcript and 5'UTR also has been observed (Lee et al. 2009, Hausser et al. 2013). MicroRNAs have been cloned, sequenced and/or identified in numerous plants, viruses and animals, and to date, hundreds of mammalian microRNA sequences have been identified that are highly conserved between species (e.g., Supplementary Table 1, see section on supplementary data given at the end of this article).

\section{MicroRNAs in gamete maturation}

Taking advantage of conditional gene targeting approaches in mice, a variety of studies have illustrated a critical role for microRNAs within germ cells. Using different promoter-driven Cre recombinase transgenes, Dicer has been deleted specifically in primordial germ cells. Absence of Dicer early on in development only mildly affects PGC proliferation in ovaries, but significantly decreased germ cell number in fetal testes by the time gonadal differentiation has completed (Hayashi et al. 2008). Furthermore, it now is evident that Dicer, and as such microRNAs, in germ cells are necessary for meiosis (Luense et al. 2011, Wang \& Xu 2015) and absence of microRNAs in oocytes leads to meiotic I and II spindle defects, suggesting a potential role during chromosome segregation. Contrary to oocytes, effects of microRNA absence on male germ cell maturation appear more widespread, and include apoptosis, chromosomal 
misalignment, acrosome defects, morphological defects and impaired motility. Clearly microRNAs in germ cells play a variety of critical roles in germ cell development and maturation (reviewed in Hilz et al. 2016).

The process of gamete maturation requires extensive communication with surrounding somatic cells. In oocytes, this involves coordinate signaling processes between the maturing oocyte, cumulus cells and mural granulosa cells. The presence of cell-specific microRNAs within the ovarian follicle indicates distinct functions in controlling follicle growth and oocyte maturation. Using the horse as a model, we detected 22 microRNAs exclusively in granulosa cells, and 35 microRNAs in cumulus cells collected from antral follicles that are also consistently present in cell-secreted vesicles isolated from follicular fluid (Silveira et al. 2012).

Sperm maturation occurs within the epididymis and is accompanied by transfer of material between sperm and epididymal epithelial cells. Similar to the ovarian follicle, regional specific microRNAs in epididymal epithelial cells suggests microRNA involvement in epididymal function and gamete maturation. For example, microRNAs were detected within distinct areas of the stallion epididymis with the caput containing 11 microRNAs, proximal corpus 6 microRNAs, the distal corpus 8 microRNAs and cauda 19 microRNAs unique to these regions (Twenter et al. 2017). Moreover, microRNA content in sperm changes as they travel through the epididymis, and these changes also are associated with cell-secreted vesicles present in epididymal fluid (Twenter HM \& Bruemmer JE, unpublished observations). The presence of these microRNAs within different cells types of the ovarian follicle or epididymal regions suggests important roles for microRNAs in gamete maturation.

\section{Cell-secreted vesicles: microvesicles and exosomes}

Microvesicles (MV) and exosomes (EXO) are two different classes of cell-secreted, membranous, extracellular vesicles and have been studied more extensively in the context of intercellular communication, whereas epididymosomes are vesicles unique to the epididymis and discussed later (Table 1). Microvesicles (also called microparticles, ectosomes, shedding vesicles) are a heterogeneous population of cell-secreted membrane vesicles roughly between 100 and $1000 \mathrm{~nm}$ in size. These vesicles are released through outward budding and fission of the plasma membrane; however, do not contain cellular organelles or DNA fragments as seen in apoptotic bodies. Microvesicles have been studied extensively as secreted products by red blood cells, platelets and tumors and appear to function in blood coagulation, inflammation and maternal-fetal communication (Tannetta et al. 2014). Exosomes on the other hand are smaller, $\sim 40-160 \mathrm{~nm}$ in size, and are derived through formation of intraluminal vesicles inside late endosomes (i.e., multivesicular bodies (MVBs)). Following fusion of MVBs with the plasma

Table 1 Summary of key characteristics of microvesicles, exosomes and epididymosomes.

\begin{tabular}{|c|c|c|c|}
\hline & Microvesicles & Exosomes & Epididymosomes \\
\hline Intracellular origin & Plasma membrane & Multivesicular body (MVBs) & Intraluminal compartment \\
\hline Size $(n m)$ & 100-1000 & $\sim 40-160$ & $50-250$ \\
\hline Contents & $\begin{array}{l}\text { miRNAs, mRNAs and } \\
\text { proteins }\end{array}$ & miRNAs, mRNA and proteins & miRNAs, mRNAs and proteins \\
\hline $\begin{array}{l}\text { Membrane } \\
\text { characteristic }\end{array}$ & & $\begin{array}{l}\text { Enriched in cholesterol, sphingomyelin, } \\
\text { hexosylceramides }\end{array}$ & $\begin{array}{l}\text { Enriched in phospholipids, } \\
\text { sphingomyelin, arachidonic } \\
\text { acids }\end{array}$ \\
\hline Isolation procedure & $\begin{array}{l}\text { Differential } \\
\text { ultracentrifugation }\end{array}$ & $\begin{array}{l}\text { Differential ultracentrifugation, } \\
\text { commercial precipitation reagent (e.g. } \\
\text { Exoquick, System Biosciences), } \\
\text { immunocapture }\end{array}$ & $\begin{array}{l}\text { Differential ultracentrifugation, } \\
\text { CD9 immunocapture }\end{array}$ \\
\hline Buoyant density & Not determined & $1.13-1.19 \mathrm{~g} / \mathrm{cm}^{3}$ & Not determined \\
\hline $\begin{array}{l}\text { Transmission electron } \\
\text { microscopy } \\
\text { appearance }\end{array}$ & Irregular shaped & Cup-shaped & Irregular shaped \\
\hline $\begin{array}{l}\text { Selected protein } \\
\text { markers }\end{array}$ & CD40, integrins & CD63, CD81, CD9, HSP70 & $\begin{array}{l}\text { CD9, CD26, CD224, P25b, } \\
\text { GliPriL1, MIF, AKRB1 }\end{array}$ \\
\hline Mode of release & $\begin{array}{l}\text { Plasma membrane } \\
\text { blebbling }\end{array}$ & $\begin{array}{l}\text { Fusion of MVBs with the plasma } \\
\text { membrane }\end{array}$ & Apocrine secretion \\
\hline
\end{tabular}

References; Thery et al. (2006), Mathivanan et al. (2010), György et al. (2011), Raposo and Stoorvogel (2013), Sullivan and Saez (2013), Sullivan (2015). 
membrane, intraluminal vesicles (now called exosomes) are exocytosed and released into extracellular space (Raposo \& Stoorvogel 2013). Similar to microvesicles, functions related to immune system and tumor cells have been ascribed to exosomes.

Both microvesicles and exosomes are surrounded by a phospholipid bilayer containing transmembrane proteins and carry RNAs and proteins. Characteristic protein constituents of exosomes include the tetraspanins CD63, CD81 and CD9, ALIX, heat shock proteins HSP70 and HSP90, adhesion molecules integrin $\alpha 4 \beta 1$ and laminin $\alpha 4$, cytoskeletal proteins actin and tubulin and proteins related to gene expression such as elongation factor. For a more comprehensive overview of extracellular vesicle content, the reader is referred to excellent reviews by Février \& Raposo (2004), György et al. (2011), Muller et al. (2016), as well as the recently established Exosome Protein, RNA and Lipid Database 'ExoCarta' (http://www. exocarta.org) and Vesiclepedia, a compendium of RNA, lipid and protein data cell-secreted vesicles including microvesicles and exosomes (http://www.microvesicles. org). Both exosomes and microvesicles contain material characteristic of the cell of origin, further supporting the idea that these vesicles can contribute to complex signaling pathways between cells.

Interest in exosomes and microvesicles has greatly expanded with recent discoveries that mRNAs and microRNAs are present and transferred to target cells (Valadi et al. 2007), illustrating these vesicles enable genetic exchange between cells at distant sites. Moreover, a number of cancer-related studies reveal the ability of microvesicles/exosomes to induce phenotypic changes in cell behavior, including invasion and migration. For example, Yang and coworkers reported that macrophagesecreted vesicles contain miR-223, which when transferred to breast cancer cells in vitro, lead to increased cell invasiveness (Yang et al. 2011). Although the potential role of cancer cell-secreted vesicles in tumorigenesis is becoming better understood, less is known about the role of microvesicles and exosomes in normal physiological processes.

\section{MicroRNA packaging in cell-secreted vesicles}

Since the identification of RNAs in cell-secreted vesicles and their transfer to target cells much interest and effort was placed on finding out how RNAs are packaged into these vesicles, as well as if and how selective this process is.
Although progress has been made many questions remain unanswered. The following highlights a number of potential mechanisms identified so far.

First, in general, it appears that microRNA cargo in cell-secreted vesicles reflect their type and level in donor cells. Squadrito and coworkers demonstrated that overexpression (physiologically activated or artificial) of microRNA target sequences leads to depletion of microRNAs from MVBs where exosomes are formed, and instead their enrichment in P-bodies (site of microRNA function) (Squadrito et al. 2014). Alternatively, overexpression of microRNAs leads to their increased presence in MVBs and secreted exosomes.

Secondly, inhibition of ceramide synthesis by targeted inhibition of neutral sphingomyelinase 2 leads to reduced secretion of exosomal microRNAs, whereas its overexpression results in increased secretion (Kosaka et al. 2010). Interestingly, the endosomal sorting complex (ESCRT) is not involved in this process, suggesting that at least in HEK293 and COS7 cells, exosomal microRNA secretion involves a ceramide-dependent pathway.

Thirdly, it is possible that microRNAs are selectively sorted into exosomes as evident from RNAseq analysis, and their relative abundance in vesicles does not resemble donor cells. Villarroya-Beltri and coworkers found that sumoylated hnRNPA2B1 (a heterogenous nuclear riboprotein) recognizes and binds a GGAG motif in microRNAs that is over-represented in T cell-secreted exosomes (Villarroya-Beltri et al. 2013). This suggests that microRNAs destined for loading and secretion in vesicles contain distinct sequence signatures that maybe cell or tissue specific. Alternatively, human B-cells secrete exosomal microRNAs containing 3 'end uridylated isoforms whereas 3 'end adenylated microRNAs are overrepresented in cells (Koppers-Lalic et al. 2014). This suggests that posttranscriptional modification involving uridylation of microRNAs regulates their sorting into MVBs and exosomes.

It is unclear if these different mechanisms are/can be complementary, or if these represent cell-specific mechanisms, or responses to different stimuli, of packing microRNAs in cell-secreted vesicles.

\section{Cell-secreted vesicles containing microRNAs and regulation of oocyte maturation}

The nomenclature for these cell-secreted vesicles is still confusing and controversial, and often experimental procedures are such that observed effects can not solely 
be attributed to one vesicle type over the other. Therefore, we will use extracellular vesicles (EVs) in the following section (Lötvall et al. 2014).

\section{Presence of EVs containing microRNAs in follicular fluid}

The presence of EVs containing microRNAs has been described in equine, bovine and human ovarian follicular fluid (da Silveira et al. 2012, Sang et al. 2013, Sohel et al. 2013, Santonocito et al. 2014, Navakanitworakul et al. 2016). Using transmission electron microscopy and flow cytometry, da Silveira and coworkers reported the presence of a heterogenous sized population of EVs in equine follicular fluid (da Silveira et al. 2012). Furthermore, real-time PCR analysis revealed the presence of at least 120 different microRNAs in EVs. Importantly, using both in vitro and in vivo approaches, uptake of these follicular fluidderived EVs was observed by pre-ovulatory equine granulosa cells. These data suggest EV secretion and uptake between different follicular cells is part of the complex, intricate cell communication process that underlies follicle development and oocyte maturation (Silveira et al. 2012) (Fig. 1).

Two separate studies reported that EV's containing microRNAs were also present in follicular fluid from women undergoing ICSI treatment (Sang et al. 2013, Santonocito et al. 2014). Isolated EVs contained 120 microRNAs according to TaqMan microRNA Array (Sang et al. 2013). Although many of the EV-associated microRNAs were also detected in EV-free follicular fluid, 38 microRNAs were only detected in the isolated EV fraction. Furthermore, Santonocito and coworkers isolated EVs that were on average $40 \mathrm{~nm}$ in size from follicular fluid, and using a similar TaqMan PCR array, identified
22 microRNAs that were higher in EVs compared to plasma (Santonocito et al. 2014).

Sohel and coworkers isolated EVs from follicular fluid of growing and fully grown bovine follicles (Sohel et al. 2013). PCR array analysis of 748 known microRNAs uncovered 509 microRNAs present in follicular fluid EVs, with 40 microRNAs that are present at different levels between growing and fully grown follicles, suggesting a role for these EV microRNAs in follicular growth. Furthermore, recent data from RNA sequencing experiments yielded a comprehensive list of microRNAs present in EVs isolated from small, medium and large bovine follicles (Navakanitworakul et al. 2016). Presence of 249 previously known and 455 novel microRNAs was detected in this study, and target pathway analysis tools identify cell proliferation as a major pathway predicted to be targeted by microRNAs present in EVs isolated from follicular fluid in small follicles. Interestingly, this study also revealed that not only did microRNA content change, vesicle number in follicular fluid decreased during bovine follicle development.

Although the abovementioned studies used different experimental approaches and paradigms to isolate EVs and identify microRNAs, it is clear that EVs are present in ovarian follicular fluid, and these vesicles likely play a role in cell-to-cell communication by transferring microRNAs. Pathway analysis indicates that microRNA targets include members of the WNT and TGF $\beta$ signaling pathways, wellknown regulatory pathway of folliculogenesis (Van Den Hurk \& Zhao 2005, Knight \& Glister 2006, da Silveira et al. 2012). EVs mediated delivery of molecular cargo between the different follicular cells represents a novel mechanism of regulating follicle growth and development and oocyte maturation. In addition, the fact that these EVs can be isolated relatively non-invasively allows for novel opportunities to use these naturally occurring nanovesicles

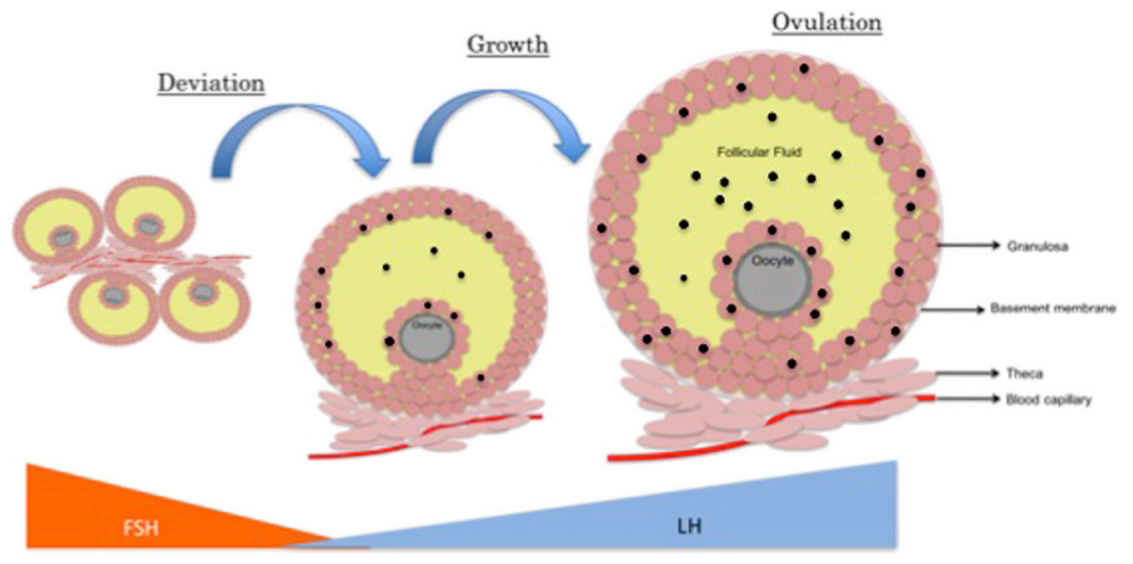

Figure 1

General overview of follicle growth and development. This process is characterized by a switch from high FSH to high LH levels and is accompanied by changes in relative amounts of cell-secreted vesicular microRNAs. Highlighted as black circles are extracellular vesicles. 
as diagnostic markers of infertility or as molecular tool in ART clinics (Barkalina et al. 2015, Machtinger et al. 2016).

\section{Hormonal regulation of EV microRNAs and their potential function in folliculogenesis}

Ovarian follicular development is a coordinated process, beginning with recruitment then selection and growth of follicles followed by atresia or dominance, ovulation and formation of the corpus luteum and finally luteolysis. These events are tightly regulated by various endocrine and paracrine signals coming from the pituitary (FSH and LH) as well as the ovary itself (e.g., androgens, estradiol, activin and inhibin). In order to examine the potential role of EV microRNAs during follicle development and oocyte maturation, we isolated EV from follicular fluid of ovaries at early maturation (deviation), mid-estrus and pre-ovulatory stages in mares. MicroRNA real-time PCR profiling analysis revealed that a number of EV microRNAs are present at different levels at early maturation and preovulation stages compared to mid-estrus (da Silveira et al. 2015).

Transition from mid-estrus to pre-ovulatory period coincides with increased LH levels (Fig. 1); therefore, it is possible the rise in LH controls EV microRNA content in follicular fluid. For example, EV miR-125 and miR-199 are increased in follicular fluid (EV) from preovulatory follicles and are present in equine follicular somatic cells such as granulosa cells (Silveira et al. 2012). Both microRNAs also were identified in ovine follicles using a microRNA sequencing platform and detected more frequently in pre-ovulatory follicles (McBride et al. 2012). miR-125b and miR-199-3p target cell cycle regulators (LIF) and eicosanoids biosynthesis enzyme, (PTGS2), respectively, genes known to be involved in oocyte maturation and cumulus expansion (Assou et al. 2006, McBride et al. 2012). Similarly, miR-21, miR-132 and miR-212 are examples of microRNAs regulated by hCG/LH in periovulatory mouse granulosa cells and in follicular fluid and granulosa cells of mares (Fiedler et al. 2008, Schauer et al. 2013). Also, these miRNAs are present in granulosa/cumulus cells and EVs collected from follicular fluid of pre-ovulatory follicles in the mare (Silveira et al. 2012). Based on results by Schauer and coworkers, these miRNAs are altered by LH induction in follicular fluid as well as in granulosa cells and are involved in cell survival and final differentiation. Predicted targets include PTEN and BMPR2 (miR-21; Qin et al. 2009, Schauer et al. 2013), involved in regulating granulosa cell proliferation (Fan et al. 2008) and maturation of the cumulus-oocyte-complex (Assou et al. 2006) and TJP1 (miR-212; Tang et al. 2008) involved in cell-cell interactions and regulation of tight junctions in ovarian surface epithelial cells (Zhu et al. 2004).

In an effort to identify a physiological function for follicular fluid EVs, Hung and coworkers isolated EVs from small $(3-5 \mathrm{~mm})$ and large $(>9 \mathrm{~mm})$ bovine antral follicles (Hung et al. 2015). Incubating either mouse or bovine cumulus-oocyte complexes with EVs from small or large antral follicles resulted in cumulus-oocyte complex expansion. However, even though expansion of cumulus-oocyte complexes was associated with changes in PTGS2, TNFAIP6 and PTX3, at present, it is unclear if $\mathrm{EV}$ microRNAs are involved in this.

These studies clearly highlight the possibility that EV microRNAs present in follicular fluid contribute to various aspects of follicular growth and maturation (Fig. 2).

\section{EV microRNAs and oocyte maturation}

Although the exact role of these EV microRNAs and the importance of EV-mediated transfer through follicular fluid during follicle growth are unclear, they likely play a role in the process of oocyte maturation and acquisition of developmental competence (Fig. 1). In an effort to study the role of EV microRNAs in oocyte maturation, EVs were isolated from follicular fluid of follicles collected from young (3-10 years) and old ( $>20$ years) mares and profiled for microRNAs. The aged mare is a well-established model of poor/decreased oocyte quality (Carnevale 2008). Real-time PCR analysis of EV microRNA content revealed 26 microRNAs that were differentially expressed at deviation, mid-estrous and pre-ovulatory in follicular fluid of young mares (da Silveira et al. 2015). Most of the differences were observed when comparing EV miRNAs between midoestrous and preovulation stages. Alternatively, a total of $53 \mathrm{EV}$ miRNAs were differentially expressed at deviation, mid-oestrous and pre-ovulatory in follicular fluid of old mares (da Silveira et al. 2015). In old mares, most differences were observed when comparing EV miRNAs between deviation and the mid-oestrous and pre-ovulatory stages of follicle maturation. Among these EV microRNAs, miR-23a, a validated regulator of XIAP in human was increased in EVs isolated from follicular fluid at mid-estrous in old mares compared to young mares. miR-23a was also increased in ovaries of patients with premature ovarian failure and increased circulating FSH levels (Yang et al. 2012). In addition, miR-222 a predicted regulator of ESR 1 and $C D K 1 B$ was 


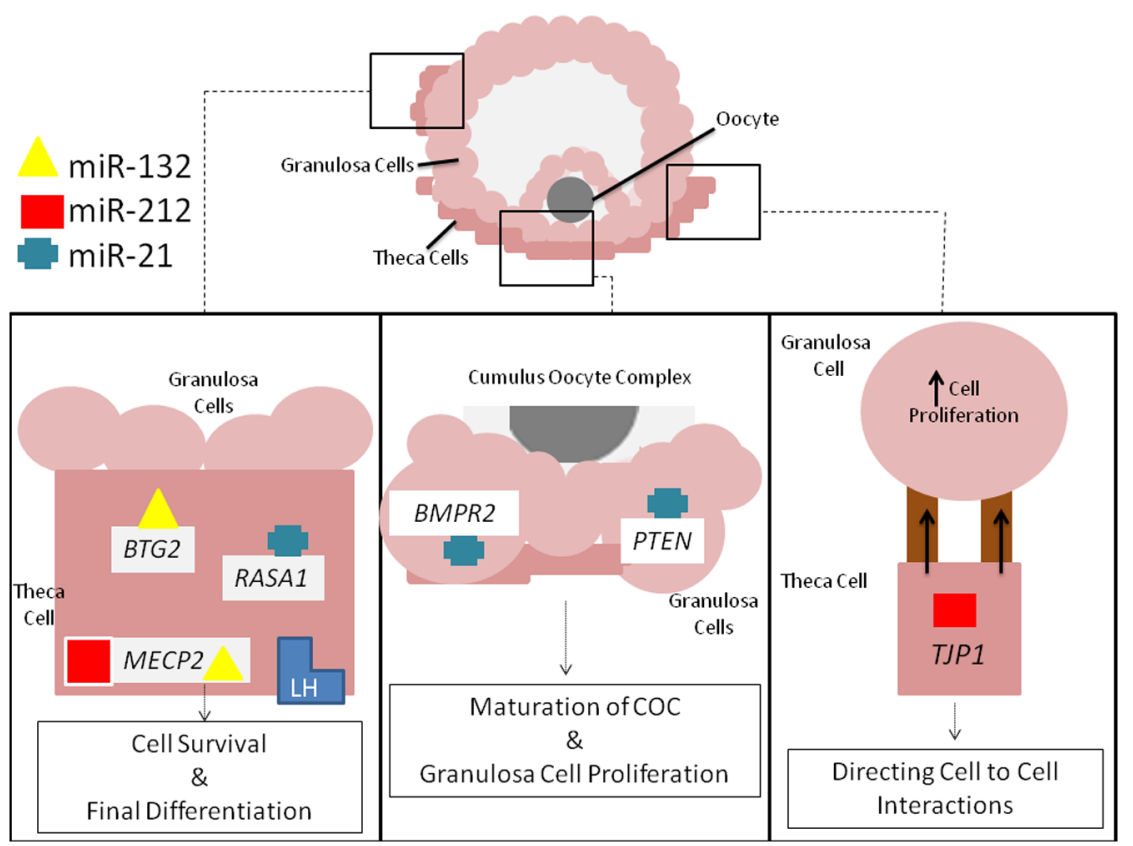

\section{Figure 2}

An overview of selected EV microRNAs and their possible role in follicle growth and oocyte maturation. For simplicity, EVs are represented as containing specific, individual microRNAs. decreased in EVs isolated from FF of old mares compared to young mares. miR-222 was found in FF of human follicles and demonstrated to stimulate secretion of estradiol in KGN cells (a steroidogenic human ovarian granulosa-like tumor cell line) in vitro (Sang et al. 2013). Moreover, twelve microRNAs were validated in vitro as modulators of steroidogenesis (e.g., miR-24 decreased estradiol production by KGN cells), while miR-132, miR-320, miR-520c-3p and miR-222 promoted estradiol secretion (Sang et al. 2013). miR-24, miR-19b, miR-222 and miR-132 were present in EVs isolated from follicular fluid of mares, and miR-132 is also higher in EVs isolated from old compared to young mares (da Silveira et al. 2012), and increased in follicular fluid of luteinizing follicles compared to dominant follicles before induction of follicle maturation (Sang et al. 2013, Schauer et al. 2013). This suggest that the wellknown changes in oocyte maturation between young and old mares (as seen in women) may be due to altered secretion and/or delivery of EV microRNA between follicular cells. Of interest again is the observation that many EV microRNAs identified are predicted to target the TGF $\beta$ signaling pathway (da Silveira et al. 2012). Furthermore, we demonstrated that EV miR-181a was 15 -fold higher in follicular fluid from pre-ovulatory (mature) compared with mid-oestrous follicles (immature) from young mares (da Silveira et al. 2014). In mice miR-181 leads to suppression of activin A receptor type IIA, which can induce SMAD phosphorylation and block in cell proliferation (Zhang et al. 2013).
Finally, we identified changes in EV microRNAs and potential targets belonging to the TGF $\beta$ signaling member family (IL6, COL1A2, ID2, STAT1 and CDC25A) in follicle growth and development in young and old mares (da Silveira et al. 2015).

EV microRNAs also were assessed in follicular fluid from young ( $<31$ years old) and older ( $>38$ years old) women (Diez-Fraile et al. 2014). Real-time PCR profiling identified at least $91 \mathrm{EV}$ microRNAs, with miR-21-5p only detected in EVs isolated from follicular fluid of young women, whereas miR-134 significantly higher and miR-190b and miR-99b-3p only in EVs from follicular fluid of old women. These microRNAs are different than the ones observed in young vs old mares, which possible is due to species differences or differences in analysis platforms. However, miR-21-5p also targets the TGF $\beta$ pathway.

Overall, these results suggest that EV microRNAs play an important role in follicular development and cellular communication within the mammalian ovarian follicle by regulating critical signaling pathways, including TGF $\beta$ and WNT signaling (Table 2). In addition, EVs could serve as vehicles to carry microRNAs to the maturing oocyte and play roles in early embryo activation and/or development.

\section{Epididymosomal microRNAs and sperm maturation and function}

EVs found in epididymal fluid are called epididymosomes (Sullivan 2015) and have been detected in bovine, ovine, 
Table 2 Examples of ovarian follicle compartment and extracellular vesicular microRNAs and their predicted targets and role in oocyte maturation.

\begin{tabular}{|c|c|c|}
\hline microRNAs & $\begin{array}{l}\text { Target } \\
\text { genes }\end{array}$ & Signaling pathways and processes \\
\hline miR-24 & $\begin{array}{l}\text { TGF } \beta 1 \\
E G F R \\
R A B 5 B\end{array}$ & $\begin{array}{l}\text { Reproductive aging, cell proliferation, } \\
\text { and metabolic diseases } \\
\text { Reproductive aging, cell proliferation, } \\
\text { and metabolic diseases }\end{array}$ \\
\hline miR-132 & $\begin{array}{l}\text { HMGA2 } \\
\text { PTEN } \\
\text { RASA1 }\end{array}$ & $\begin{array}{l}\text { Etiology of PCOS } \\
\text { Cell signaling } \\
\text { Reproductive system diseases } \\
\text { Endocrine system disorders }\end{array}$ \\
\hline miR-320 & $\begin{array}{l}I L-1 A \\
I L-10 \\
I L-12 B \\
I L-37 \\
I L-8 \\
R A B 5 B\end{array}$ & $\begin{array}{l}\text { Immune system } \\
\text { Etiology of PCOS } \\
\text { WNT }\end{array}$ \\
\hline miR-520c-3p & ESR1 & Steroidogenesis \\
\hline miR-222 & $\begin{array}{l}\text { ESR1 } \\
\text { PTEN }\end{array}$ & $\begin{array}{l}\text { Steroidogenesis } \\
\text { Tumor suppressor, insulin signaling } \\
\text { and glucose metabolism in adipose } \\
\text { tissue }\end{array}$ \\
\hline miR-193b & ESR1 & Steroidogenesis \\
\hline $\operatorname{miR}-483-5 p$ & $\begin{array}{l}I L-1 A \\
I L-10 \\
I L-12 B \\
I L-37 \\
I L-8\end{array}$ & Immune system \\
\hline miR-19b & $N D$ & $\begin{array}{l}\text { WNT } \\
\text { TGFB } \\
\text { MAPK }\end{array}$ \\
\hline miR-125 & $\begin{array}{l}\text { LIF } \\
\text { CDKN1A }\end{array}$ & Cell cycle \\
\hline
\end{tabular}

miR-199 PTGS2 Oocyte maturation and cumulus expansion

$\begin{array}{lll}\text { miR-21 } & \begin{array}{l}\text { PTEN } \\ \text { BTG2 } \\ \text { RASA1 } \\ \text { MECP2 }\end{array} & \begin{array}{c}\text { Cell signaling, survival and } \\ \text { proliferation/differentiation }\end{array} \\ & & \\ \text { miR-212 } & \begin{array}{l}\text { PTEN } \\ \text { RASA1 }\end{array} & \begin{array}{c}\text { Cell signaling, survival and } \\ \text { proliferation/differentiation }\end{array} \\ & \text { XIAP } & \text { Apoptosis in granulosa cells }\end{array}$

miR-181a BMPR2 Cell proliferation, ovarian follicle ACVR2A development

\section{Effect}

Decreased estradiol secretion Decreased estradiol secretion

Increased estradiol secretion Regulated by hCG/LH in periovulatory granulosa cell Differed between small and large follicles

Increased estradiol secretion Embryonic development improvement

Increased estradiol secretion

Increased estradiol secretion Differed between small and large follicles

Decreased progesterone secretion

Decreased progesterone secretion

Folliculogenesis regulation

Differed between small and large follicles

Differed between small and large follicles

Follicular-luteal transition

Differed between small and large follicles

Follicular-luteal transition

Regulated by hCG/LH in periovulatory granulosa cell

Differed between small and large follicles

Follicular-luteal transition

Regulated by hCG/LH in periovulatory granulosa cells

Higher in exosomes from follicular fluid of old compared with young mares Increase FSH levels

Inhibition of the cellular proliferation

\section{Species Reference \\ Human da Silveira et al. (2012) Equine Sang et al. (2013)}

Human Fiedler et al. (2008)

Equine da Silveira et al. (2012)

Mice Sang et al. (2013)

Bovine Schauer et al. (2013)

Navakanitworakul et al. (2016)

Machtinger et al. (2017)

Human Sang et al. (2013)

Human Sang et al. (2013)

Human da Silveira et al. (2012)

Equine Sang et al. (2013)

Bovine Navakanitworakul et al. (2016)

Human Sang et al. (2013)

Human Sang et al. (2013)

Equine da Silveira et al. (2012)

Bovine Navakanitworakul et al. (2016)

Equine da Silveira et al. (2012)

Bovine McBride et al. (2012)

Ovine Navakanitworakul et al. (2016)

Equine da Silveira et al. (2012)

Bovine (McBride et al. 2012)

Ovine Navakanitworakul et al. (2016)

Mice Fiedler et al. (2008)

Equine McBride et al. (2012)

Bovine da Silveira et al. (2012)

Ovine Schauer et al. (2013) Navakanitworakul et al. (2016)

Mice Fiedler et al. (2008)

Equine da Silveira et al. (2012) Schauer et al. (2013)

Equine da Silveira et al. (2012)

Human Yang et al. (2012) da Silveira et al. (2015)

Equine da Silveira et al. (2012)

Mice Zhang et al. (2013) da Silveira et al. (2014) da Silveira et al. (2015)

ND, not determined. 
human, mouse and rat (reviewed in Sullivan \& Saez 2013, Belleannee 2015). Epididymosomes range between 50 and $250 \mathrm{~nm}$ in size and contain a variety of proteins that can be transferred to sperm during epididymal transit (Table 1) (Sullivan et al. 2007, Sullivan 2015). There are at least two populations of epididymosomes with distinct functions within the epididymis; one containing tetraspanin proteins such as CD9, which can interact with live sperm and a second population containing proteins such as ELSPBP1 (epididymal sperm binding protein 1), that interact with dead sperm (Sullivan et al. 2007, Sullivan 2015). Secretion of these epididymosomes appears to occur by the Principal cells through an apocrine mechanism; release of apical cytoplasm (blebs) that contain free ribosomes and small membrane vesicles. When these blebs disintegrate in the epididymal lumen, vesicles (epididymosomes) are released (reviewed in Sullivan \& Saez 2013).

In addition to proteins, epididymosomes carry microRNAs within epididymal fluid. Belleannée et al. (2013) demonstrated that bovine epididymosomes collected from the epididymal caput (head) and cauda (tail) regions contain different microRNA profiles and do not always reflect the repertoire present in epididymal cells. Epididymosomal microRNAs from let-7 and miR-200 families as well as miR-26a, miR-103 and miR-191 were present in high abundance in both epididymosomal populations (Belleannée et al.2013). Additionally, miR-145, miR-143, miR-214 and miR-199 were present in higher amounts in epididymosomes from caput, while miR-654, miR-1224 and miR-395 are higher in epididymosomes collected from the cauda region (Belleannée et al. 2013). Moreover, epididymosomes secreted within the epididymis intraluminal environment can be taken up by surrounding epithelial cells possibly regulating transcription/translation within these cells (Belleannée et al. 2013, Belleannée 2015). Of interest here is that miR-145 is one of several known microRNAs that target and regulate expression of the cystic fibrosis transmembrane conductance regulator (CFTR) chloride channel (Gillen et al. 2011), an anion-selective channel expressed in the epididymis and sperm (Diao et al. 2013). Moreover, impaired CFTR function is associated with poor sperm quality and infertility (Diao et al. 2013). Similarly, miR-200a and Let-7b were highly abundant in epididymosomes (Belleannée etal.2013). These microRNAs are of interest considering their tumor suppressor function, and the observation that epididymal tumors are exceedingly rare $(0.03 \%$ of all male cancers; Yeung et al. 2012). In a recent set of experiments, spermatozoa and epididymosomes were also isolated from equine epididymal luminal fluid along 4 different regions of the epididiymis (Twenter HM \& Bruemmer JE, unpublished observations). 324 microRNAs were identified in spermatozoa from the epididymal caput or cauda or both regions. Importantly, 33 microRNAs were discovered in caudal epididymal sperm but not within sperm from the caput. This suggests epididymosomal transport and delivery of microRNAs. The 324 miRNAs within epididymal spermatozoa were compared to the microRNAs within epididymal tissue from the caput or cauda; 92 microRNAs were found within both epididymal spermatozoa and tissue. These 92 microRNAs were compared to epididymosomes from the lumen of the caput, proximal corpus, distal corpus and cauda epididymis. Although 69 microRNAs were noted in epididymal spermatozoa from one or more regions, in epididymosomes, or in epididymal tissue, there were many microRNAs that were only identified in a specific region. Most notably, 11 microRNAs were found within epididymal tissue of either the caput or cauda that were also detected in epididymosomes of the corresponding region. These 11 microRNAs were also observed in spermatozoa collected from to the caudal region suggesting these could have been transferred to sperm during their transit from the caput to the caudal region of the epididymis. Notable pathways predicted to be targeted by epididymosomal microRNAs included those with potential roles in oocyte and embryos, specifically embryogenesis, resumption of oocyte meiosis, protein processing in endoplasmic reticulum, and mTOR signaling pathway (Twenter HM $\&$ Bruemmer JE, unpublished observations). These data further suggest possible transfer of microRNAs between epididymal cells and sperm through epididymosomes.

Jerczynski et al. (2016) used both in vivo and in vitro approaches to demonstrate the role of DICER1 in epididymal and epididymosome microRNA expression and function. Conditional knockout of Dicer1 in Principal cells decreased expression of 114 mature microRNAs, including miR-210, miR672, miR-191 and miR-204. Of interest here is that these microRNAs also are present in EVs secreted by cultured Principal cells, and whose predicted target genes include genes associated with lipid metabolism, calcium transport and cytoskeletal formation.

A recent study demonstrated the presence of $>350$ microRNAs in mouse epididymosomes, with the majority $(\sim 60 \%)$ also present in sperm (Reilly et al. 2016). In addition, 5 microRNAs (miR-191, miR-375, miR-467a, miR-467d and miR-467e) increased in caput epididymosomes were increased in sperm following exposure to these epididymosomes, demonstrating that 


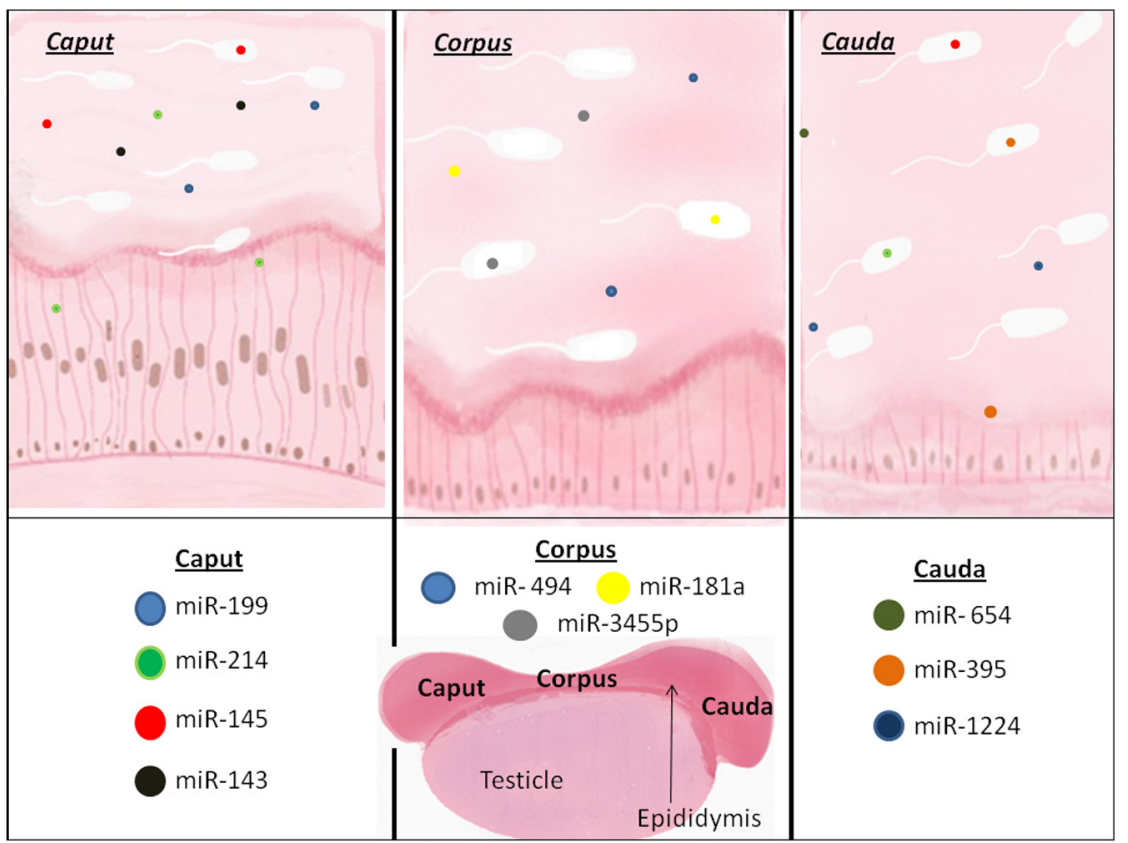

Figure 3

Overview of cell-secreted vesicles and their microRNA cargo in epididymal fluid. Highlighted and color coded are examples of selected epididymosomal microRNAs present in somatic cells, reproductive fluids and germ cells. epididymosomes can deliver microRNAs to spermatozoa in transit through the epididymis (Reilly et al. 2016). Moreover, it appears that epididymosomes carrying microRNAs are transferred between epididymal epithelial cells and spermatozoa by epididymosomes thereby regulating sperm maturation(Fig. 3). Interestingly, miR-191 and miR-210 in epididymosomes secreted by Principal cells (Jerczynski et al. 2016) and transferred to sperm (Reilly et al. 2016) are microRNAs that are also present in EVs isolated from follicular fluid (da Silveira et al. 2012). Possibly these microRNAs are transferred to both sperm and oocyte and play a role in early embryogenesis. miR-210 is a well-known regulator of stem cell differentiation and cell cycle progression (Huang et al. 2010).

Finally, recent studies demonstrated that paternal metabolic phenotype can modulate epididymosomes content and thus affect offspring. Protein restriction in mice alters small RNA levels in mature sperm, with a decrease in microRNA let-7 and increase in 5' fragments of glycine tRNAs levels. These are scarce in testicular sperm but acquired as sperm mature in the epididymis after fusion with epididymosomes (Sharma et al. 2015). Furthermore, mice fed with western-like diet (high-fat or high-sugar) presented with altered sperm microRNA profiles, and the subsequent transfer of altered microRNAs through ICSI led to the establishment of western-like-dietinduced metabolic phenotype in offspring (Grandjean et al. 2015).

In summary, it appears that similar to EVs in follicular fluid, epididymosomes in epididymal fluid are important contributors to gamete maturation and function. These endogenous small cell-secreted vesicles appear to aid in cell communication between epithelial cells and sperm by delivering microRNAs. Since sperm are transcriptionally inactive, it is likely that microRNAs transferred to sperm as they transit the epididymis play a role in embryo activation and/or early development.

\section{Future directions}

Although the presence of EVs has been known for many years, their content analyzed and catalogued extensively, many basic questions remain. For example, how are different microRNAs selectively loaded into these vesicles? Aside from their biogenesis, are there differences in microvesicle- and exosome-mediated delivery of microRNAs and/or function? How specific is this communication process? How is molecular cargo actually transferred? How useful are these EV microRNAs as diagnostic markers? The packing of distinct microRNAs within vesicles allows for characterization of microRNA signatures that likely better reflect certain cell phenotypes instead of a single microRNA.

Continuing efforts in vesicle isolation procedures, especially sensitivity as it relates to volume requirements to isolated these vesicles, will further advance our understanding of vesicular microRNAs and proteins in cell communication processes. For example, vesicles are released into extracellular fluid (space). Sampling 
extracellular space to characterize vesicular morphology and content can provide novel insight into critical processes such as theca-granulosa cell communication and Sertoli cell-germ cell interactions. Finally, the identification of small RNA regulatory molecules within cell-secreted vesicles provides for exciting new opportunities by generating 'delivery tools' to transfer molecular cargo and modulate cell function. For example, elegant experiments by Woods and colleagues reveal that exosomes can be manipulated to provide an immunologically inert vesicle carrier of small interfering RNAs to specific target sites (Alvarez-Erviti et al. 2011). Therefore, in addition to its potentially important, under-studied role in reproductive biology and physiology, and utility as a novel class of biomarkers in reproductive disease, these vesicular microRNAs also can be used as novel tools in reproductive biotechnology and medicine.

\section{Supplementary data}

This is linked to the online version of the paper at https://doi.org/10.1530/ JOE-17-0200.

\section{Declaration of interest}

The authors declare that there is no conflict of interest that could be perceived as prejudicing the impartiality of the research reported.

\section{Funding}

The authors are grateful for the funding supporting the research involving exosomal microRNAs from CSU CVMBS College Research Council, the Preservation of Equine Genetics, Cecil and Irene Hylton Foundation, and financial support from the Abney Foundation, Ed H Honnen Award, the France Stone Scholarship, and the Assisted Reproduction Program at Colorado State University. Additional support came from grants from the American Quarter Horse Foundation and FAPESP (grant 2012/50533-2; grant 2013/10473-3; grant 2015/16985-1; grant 2017/02037-0 and grant 2014/22887-0).

\section{References}

Alvarez-Erviti L, Seow Y, Yin H, Betts C, Lakhal S \& A Wood MJ 2011 Delivery of siRNA to the mouse brain by systemic injection of targeted exosomes. Nature Biotechnology 29 3-4. (https://doi. org/10.1038/nbt.1807)

Assou S, Anahory T, Pantesco V, Le Carrour T, Pellestor F, Klein B, Reyftmann L, Dechaud H, De Vos J \& Hamamah S 2006 The human cumulus - oocyte complex gene-expression profile. Human Reproduction 21 1705-1719. (https://doi.org/10.1093/humrep/del065)

Barkalina N, Jones C, Wood MJA \& Coward K 2015 Extracellular vesicle-mediated delivery of molecular compounds into gametes and embryos: learning from nature. Human Reproduction Update $\mathbf{2 1}$ 627-639. (https://doi.org/10.1093/humupd/dmv027)
Bartel DP 2009 MicroRNAs: target recognition and regulatory functions. Cell 136 215-233. (https://doi.org/10.1016/j.cell.2009.01.002)

Belleannée C 2015 Extracellular microRNAs from the epididymis as potential mediators of cell-to-cell communication. Asian Journal of Andrology 17 730-736. (https://doi.org/10.4103/1008$682 \times .155532)$

Belleannée C, Calvo É, Caballero J \& Sullivan R 2013 Epididymosomes convey different repertoires of microRNAs throughout the bovine epididymis. Biology of Reproduction 89 1-11. (https://doi.org/10.1095/ biolreprod.113.110486)

Carnevale EM 2008 The mare model for follicular maturation and reproductive aging in the woman. Theriogenology 69 23-30. (https:// doi.org/10.1016/j.theriogenology.2007.09.011)

Cheloufi S, Santos CO Dos, Chong MMW \& Hannon GJ 2010 Ago catalysis. Nature 465 584-589. (https://doi.org/10.1038/ nature09092.A)

Cocucci E \& Meldolesi J 2015 Ectosomes and exosomes: shedding the confusion between extracellular vesicles. Trends in Cell Biology $\mathbf{2 5}$ 364-372. (https://doi.org/10.1016/j.tcb.2015.01.004)

Diao R, Fok KL, Zhao L, Chen H, Tang H, Chen J, Zheng A, Zhang X, Gui Y, Chan HC, et al. 2013 Decreased expression of cystic fibrosis transmembrane conductance regulator impairs sperm quality in aged men. Reproduction 146 637-645. (https://doi.org/10.1530/REP-130146)

Diez-Fraile A, Lammens T, Tilleman K, Witkowski W, Verhasselt B, De Sutter P, Benoit Y, Espeel M \& D’Herde K 2014 Age-associated differential microRNA levels in human follicular fluid reveal pathways potentially determining fertility and success of in vitro fertilization. Human Fertility 17 90-98. (https://doi.org/10.3109/14647273.2014.8 97006)

Fan H-Y, Liu Z, Cahill N \& Richards JS 2008 Targeted disruption of Pten in ovarian granulosa cells enhances ovulation and extends the life span of luteal cells. Molecular Endocrinology 22 2128-2140. (https://doi. org/10.1210/me.2008-0095)

Février B \& Raposo G 2004 Exosomes: endosomal-derived vesicles shipping extracellular messages. Current Opinion in Cell Biology 16 415-421. (https://doi.org/10.1016/j.ceb.2004.06.003)

Fiedler SD, Carletti MZ, Hong X \& Christenson LK 2008 Hormonal regulation of MicroRNA expression in periovulatory mouse mural granulosa cells. Biology of Reproduction 79 1030-1037. (https://doi. org/10.1095/biolreprod.108.069690)

Gillen AE, Gosalia N, Leir S-H \& Harris A 2011 MicroRNA regulation of expression of the cystic fibrosis transmembrane conductance regulator gene. Biochemical Journal 438 25-32. (https://doi. org/10.1042/BJ20110672)

Grandjean V, Fourré S, De Abreu DAF, Derieppe M-A, Remy J-J \& Rassoulzadegan M 2015 RNA-mediated paternal heredity of dietinduced obesity and metabolic disorders. Scientific Reports 518193. (https://doi.org/10.1038/srep18193)

György B, Szabó TG, Pásztói M, Pál Z, Misják P, Aradi B, László V, Pállinger É, Pap E, Kittel Á, et al. 2011 Membrane vesicles, current state-of-the-art: emerging role of extracellular vesicles. Cellular and Molecular Life Sciences 68 2667-2688. (https://doi.org/10.1007/s00018011-0689-3)

Hausser J, Syed AP, Bilen B \& Zavolan M 2013 Analysis of CDS-located miRNA target sites suggests that they can effectively inhibit translation. Genome Research 23 604-615. (https://doi.org/10.1101/ gr.139758.112)

Hayashi K, Chuva de Sousa Lopes SM, Kaneda M, Tang F, Hajkova P, Lao K, O'Carroll D, Das PP, Tarakhovsky A, Miska EA, et al. 2008 MicroRNA biogenesis is required for mouse primordial germ cell development and spermatogenesis. PLOS ONE 3 1-9. (https://doi. org/10.1371/journal.pone.0001738)

Hilz S, Modzelewski AJ, Cohen PE \& Grimson A 2016 The roles of microRNAs and siRNAs in mammalian spermatogenesis. Development 143 3061-3073. (https://doi.org/10.1242/dev.136721) 
Huang X, Le Q-T \& Giaccia AJ 2010 MiR-210, micromanager of the hypoxia pathway. Trends in Molecular Medicine 16 230-237. (https:// doi.org/10.1016/j.molmed.2010.03.004.MiR-210)

Hung W-T, Hong X, Christenson LK \& McGinnis LK 2015 Extracellular vesicles from bovine follicular fluid support cumulus expansion. Biology of Reproduction 93 117. (https://doi.org/10.1095/ biolreprod.115.132977)

Van Den Hurk R \& Zhao J 2005 Formation of mammalian oocytes and their growth, differentiation and maturation within ovarian follicles. Theriogenology 63 1717-1751. (https://doi.org/10.1016/j. theriogenology.2004.08.005)

Jerczynski O, Lacroix-Pépin N, Boilard E, Calvo E, Bernet A, Fortier MA, Björkgren I, Sipilä P \& Belleannée C 2016 Role of Dicer1-dependent factors in the paracrine regulation of epididymal gene expression. PLOS ONE 11 1-26. (https://doi.org/10.1371/journal.pone.0163876)

Knight PG \& Glister C 2006 TGF- $\beta$ superfamily members and ovarian follicle development. Reproduction 132 191-206. (https://doi.org/10.1530/ rep.1.01074)

Koppers-Lalic D, Hackenberg M, Bijnsdorp I V, van Eijndhoven MAJ, Sadek P, Sie D, Zini N, Middeldorp JM, Ylstra B, de Menezes RX, et al. 2014 Nontemplated nucleotide additions distinguish the small RNA composition in cells from exosomes. Cell Reports 81649 1658. (https://doi.org/10.1016/j.celrep.2014.08.027)

Kosaka N, Iguchi H, Yoshioka Y, Takeshita F, Matsuki Y \& Ochiya T 2010 Secretory mechanisms and intercellular transfer of microRNAs in living cells. Journal of Biological Chemistry $\mathbf{2 8 5}$ 17442-17452. (https://doi.org/10.1074/jbc.M110.107821)

Lee I, Ajay SS, Yook JI, Kim HS, Hong SH, Kim NH, Dhanasekaran SM, Chinnaiyan AM \& Athey BD 2009 New class of microRNA targets containing simultaneous 5'-UTR and 3'-UTR interaction sites. Genome Research 19 1175-1183. (https://doi.org/10.1101/gr.089367.108)

Lötvall J, Hill AF, Hochberg F, Buzás EI, Di Vizio D, Gardiner C, Gho YS, Kurochkin IV, Mathivanan S, Quesenberry P, et al. 2014 Minimal experimental requirements for definition of extracellular vesicles and their functions: a position statement from the International Society for Extracellular Vesicles. Journal of Extracellular Vesicles 326913. (https://doi.org/10.3402/jev.v3.26913)

Lu J \& Clark AG 2012 Impact of microRNA regulation on variation in human gene expression. Genome Research 22 1243-1254. (https:// doi.org/10.1101/gr.132514.111.22)

Luense LJ, Carletti MZ \& Christenson LK 2011 NIH public access. Trends in Endocrinology Metabolism 20 265-272. (https://doi.org/10.1016/j. tem.2009.05.001.Role)

Machtinger R, Laurent LC \& Baccarelli AA 2016 Extracellular vesicles: roles in gamete maturation, fertilization and embryo implantation. Human Reproduction Update 22 182-193. (https://doi.org/10.1093/humupd/ dmv055)

Machtinger R, Rodosthenous RS, Adir M \& Mansour A 2017 Extracellular microRNAs in follicular fluid and their potential association with oocyte fertilization and embryo quality : an exploratory study. Journal of Assisted Reproduction and Genetics 34 525-533. (https://doi. org/10.1007/s10815-017-0876-8)

Mathivanan S, Ji H \& Simpson RJ 2010 Exosomes: extracellular organelles important in intercellular communication. Journal of Proteomics 73 1907-1920. (https://doi.org/10.1016/j. jprot.2010.06.006)

McBride D, Carré W, Sontakke SD, Hogg CO, Law A, Donadeu FX \& Clinton M 2012 Identification of miRNAs associated with the follicular-luteal transition in the ruminant ovary. Reproduction 144 221-233. (https://doi.org/10.1530/REP-12-0025)

Muller L, Mitsuhashi M, Simms P, Gooding WE \& Whiteside TL 2016 Tumor-derived exosomes regulate expression of immune functionrelated genes in human T cell subsets. Scientific Reports 620254. (https://doi.org/10.1038/srep20254)

Navakanitworakul R, Hung W-T, Gunewardena S, Davis JS, Chotigeat W \& Christenson LK 2016 Characterization and small RNA content of extracellular vesicles in follicular fluid of developing bovine antral follicles. Scientific Reports 6 25486. (https://doi.org/10.1038/ srep25486)

Qin W, Zhao B, Shi Y, Yao C, Jin L \& Jin Y 2009 BMPRII is a direct target of miR-21. Acta Biochimica et Biophysica Sinica 41 618-623. (https:// doi.org/10.1093/abbs/gmp049.Advance)

Raposo G \& Stoorvogel W 2013 Extracellular vesicles: exosomes, microvesicles, and friends. Journal of Cell Biology 2000 373-383. (https://doi.org/10.1083/jcb.201211138)

Raposo G, Nijman HW, Stoorvogel W, Liejendekker R, Harding CV, Melief CJ \& Geuze HJ 1996 B lymphocytes secrete antigen-presenting vesicles. Journal of Experimental Medicine 183 1161-1172. (https://doi. org/10.1084/jem.183.3.1161)

Reilly JN, McLaughlin EA, Stanger SJ, Anderson AL, Hutcheon K, Church K, Mihalas BP, Tyagi S, Holt JE, Eamens AL, et al. 2016 Characterisation of mouse epididymosomes reveals a complex profile of microRNAs and a potential mechanism for modification of the sperm epigenome. Scientific Reports 6 1-15. (https://doi.org/10.1038/srep31794)

Sang Q, Yao Z, Wang H, Feng R, Wang H, Zhao X, Xing Q, Jin L, He L, Wu L, et al. 2013 Identification of microRNAs in human follicular fluid: characterization of microRNAs that govern steroidogenesis in vitro and are associated with polycystic ovary syndrome in vivo. Journal of Clinical Endocrinology and Metabolism 98 3068-3079. (https://doi.org/10.1210/jc.2013-1715)

Santonocito M, Vento M, Guglielmino MR, Battaglia R, Wahlgren J, Ragusa M, Barbagallo D, Borzì P, Rizzari S, Maugeri M, et al. 2014 Molecular characterization of exosomes and their microRNA cargo in human follicular fluid: bioinformatic analysis reveals that exosomal microRNAs control pathways involved in follicular maturation. Fertility and Sterility 102 1751-1761. (https://doi.org/10.1016/j. fertnstert.2014.08.005)

Schauer SN, Sontakke SD, Watson ED, Esteves CL \& Donadeu FX 2013 Involvement of miRNAs in equine follicle development. Reproduction 146 273-282. (https://doi.org/10.1530/REP-13-0107)

Sharma U, Conine CC, Shea JM, Boskovic A, Derr AG, Bing XY, Belleannee C, Kucukural A, Serra RW, Sun F, et al. 2015 Biogenesis and function of tRNA fragments during sperm maturation and fertilization in mammals. Science 351 391-396. (https://doi. org/10.1126/science.aad6780)

da Silveira JC, Veeramachaneni DNR, Winger QA, Carnevale EM \& Bouma GJ 2012 Cell-secreted vesicles in equine ovarian follicular fluid contain miRNAs and proteins: a possible new form of cell communication within the ovarian follicle. Biology of Reproduction $\mathbf{8 6}$ 71-71. (https://doi.org/10.1095/biolreprod.111.093252)

da Silveira JC, Carnevale EM, Winger QA \& Bouma GJ 2014 Regulation of ACVR1 and ID2 by cell-secreted exosomes during follicle maturation in the mare. Reproductive Biology and Endocrinology 12 44. (https://doi. org/10.1186/1477-7827-12-44)

da Silveira JC, Winger QA, Bouma GJ \& Carnevale EM 2015 Effects of age on follicular fluid exosomal microRNAs and granulosa cell transforming growth factor- $\beta$ signalling during follicle development in the mare. Reproduction, Fertility, and Development 27 897-905. (https://doi.org/10.1071/RD14452)

Sohel MMH, Hoelker M, Noferesti SS, Salilew-Wondim D, Tholen E, Looft C, Rings F, Uddin MJ, Spencer TE, Schellander K, et al. 2013 Exosomal and non-exosomal transport of extra-cellular microRNAs in follicular fluid: implications for bovine oocyte developmental competence. PLOS ONE $\mathbf{8}$ e78505. (https://doi.org/10.1371/journal.pone.0078505)

Squadrito ML, Baer C, Burdet F, Maderna C, Gilfillan GD, Lyle R, Ibberson M \& De Palma M 2014 Endogenous RNAs modulate MicroRNA sorting to exosomes and transfer to acceptor cells. Cell Reports 8 1432-1446. (https://doi.org/10.1016/j.celrep.2014.07.035)

Sullivan R 2015 Epididymosomes: a heterogeneous population of microvesicles with multiple functions in sperm maturation and storage. Asian Journal of Andrology 17 726-729. (https://doi. org/10.4103/1008-682X.155255) 
Sullivan R \& Saez F 2013 Epididymosomes, prostasomes, and liposomes: Their roles in mammalian male reproductive physiology. Reproduction 146 R21-R35. (https://doi.org/10.1530/REP-13-0058)

Sullivan R, Frenette G \& Girouard J 2007 Epididymosomes are involved in the acquisition of new sperm proteins during epididymal transit. Asian Journal of Andrology 9 483-491. (https://doi.org/10.1111/j.17457262.2007.00281.x)

Tang Y, Banan A, Forsyth CB, Fields JZ, Lau CK, Zhang LJ \& Keshavarzian A 2008 Effect of alcohol on miR-212 expression in intestinal epithelial cells and its potential role in alcoholic liver disease. Alcoholism: Clinical and Experimental Research 32 355-364. (https://doi.org/10.1111/j.1530-0277.2007.00584.x)

Tannetta D, Dragovic R, Alyahyaei Z \& Southcombe J 2014 Extracellular vesicles and reproduction-promotion of successful pregnancy. Cellular and Molecular Immunology 11 548-563. (https://doi.org/10.1038/ cmi.2014.42)

Thery C, Amigorena S, Raposo G \& Clayton A 2006 Isolation and characterization of exosomes from cell culture supernatants and biological fluids. Current Protocols in Cell Biology Chapter 3 Unit 3.22. (https://doi.org/10.1002/0471143030.cb0322s30)

Twenter HM, Belk AD, Klohonatz KM, Bass LD, Bouma GJ \& Bruemmer JE 2017 An investigation into miRNAs in the equine epididymis as potential regulators of spermatozoal maturation. Journal of Equine Veterinary Science 48 61-68. (https://doi.org/10.1016/j. jevs.2016.07.023)

Valadi H, Ekström K, Bossios A, Sjöstrand M, Lee JJ \& Lötvall JO 2007 Exosome-mediated transfer of mRNAs and microRNAs is a novel mechanism of genetic exchange between cells. Nature Cell Biology 9 654-659. (https://doi.org/10.1038/ncb1596)
Villarroya-Beltri C, Gutiérrez-Vázquez C, Sánchez-Cabo F, PérezHernández D, Vázquez J, Martin-Cofreces N, Martinez-Herrera DJ, Pascual-Montano A, Mittelbrunn M \& Sánchez-Madrid F 2013 Sumoylated hnRNPA2B1 controls the sorting of miRNAs into exosomes through binding to specific motifs. Nature Communications 4 2980. (https://doi.org/10.1038/ncomms3980)

Wang L \& Xu C 2015 Role of microRNAs in mammalian spermatogenesis and testicular germ cell tumors. Reproduction 149 R127-R137. (https:// doi.org/10.1530/REP-14-0239)

Yang M, Chen J, Su F, Yu B, Su F, Lin L, Liu Y, Huang J-D \& Song E 2011 Microvesicles secreted by macrophages shuttle invasion-potentiating microRNAs into breast cancer cells. Molecular Cancer 10 117. (https:// doi.org/10.1186/1476-4598-10-117)

Yang X, Zhou Y, Peng S, Wu L, Lin HY, Wang S \& Wang H 2012 Differentially expressed plasma microRNAs in premature ovarian failure patients and the potential regulatory function of mir-23a in granulosa cell apoptosis. Reproduction 144 235-244. (https://doi. org/10.1530/REP-11-0371)

Yeung C-H, Wang K \& Cooper TG 2012 Why are epididymal tumours so rare? Asian Journal of Andrology 14 465-475. (https://doi.org/10.1038/ aja.2012.20)

Zhang Q, Sun H, Jiang Y, Ding L, Wu S, Fang T, Yan G \& Hu Y 2013 MicroRNA-181a suppresses mouse granulosa cell proliferation by targeting activin receptor IIA. PLOS ONE 8 e59667. (https://doi. org/10.1371/journal.pone.0059667)

Zhu Y, Maric J, Nilsson M, Brännström M, Janson P-O \& Sundfeldt K 2004 Formation and barrier function of tight junctions in human ovarian surface epithelium. Biology of Reproduction 71 53-59. (https://doi. org/10.1095/biolreprod.103.022913)

Received in final form 9 August 2017

Accepted 4 September 2017

Accepted Preprint published online 4 September 2017 (c) 2018 Society for Endocrinology Published by Bioscientifica Ltd. Printed in Great Britain 